\title{
PARTISIPASI MASYARAKAT DALAM PENGELOLAAN HUTAN MANGROVE DI DESA SEGARAJAYA, KECAMATAN TARUMAJAYA KABUPATEN BEKASI
}

\author{
Shahibah Yuliani ${ }^{1}$, Nova Scorviana Herminasari1 ${ }^{1}$ \\ ${ }^{1}$ Pendidikan Ilmu Pengetahuan Sosial (P.IPS), Fakultas Ilmu Sosial Universita Negeri Jakarta, \\ Email : shahibah-yuliani@unj.ac.id, shyuliani@gmail.com
}

\begin{abstract}
The purpose of this research is to know the community participation management of mangrove forests in PAL Jaya Beach, Segarajaya Village Tarumajaya District, Bekasi. This study uses descriptive method, which aims to find information from by using the questionnaire (closed questionnaire), direct observation, interviews, and documentation. The subjects of this study were 25 people consisting of members of the Supervisory Society Group (POKMASWAS), Ikatan Pemuda Putera Daerah (IKAPUD), and other communitie. The results showed that community participation management of mangrove forests is relatively high from the aspects of planning and activities implementation (restoration). Community participation is also supported by several institutions cooperate such as socialization, mangrove planting, and development of mangrove forest area. However, community involvement in treating mangroves have been low. Related to community participation in utilizing mangrove forests is still educatiobal tourist area.
\end{abstract}

Keyword: Community participation, Management, Mangrove forest, Restoration 


\section{PENDAHULUAN}

Indonesia merupakan negara kepulauan terbesar di dunia dengan luas wilayah sebesar $1,904,569 \mathrm{~km}^{2}$ yang terdiri dari 17.508 pulau yang membentang sepanjang 5. $120 \mathrm{~km}$ dari timur ke barat dengan garis pantai sepanjang $81000 \mathrm{~km}$ dan luas laut 3,1 juta $\mathrm{km}^{2}$ atau $62 \%$ dari luas teritorial Indonesia (Dahuri, R. JS: 2001, 1). Sebagian daerah tersebut ditumbuhi hutan mangrove dengan lebar beberapa meter sampai beberapa kilometer. Berdasarkan luas kawasan, hutan mangrove Indonesia merupakan hutan mangrove terluas di dunia. Data tersebut di atas menunjukkan betapa besar potensi bahari yang dimiliki Indonesia, baik dari segi ekologis, ekonomi, sosial maupun politik. Negeri kepulauan, selayaknya menjadi negeri maritim yang mampu bersaing dengan dunia global dan mampu menyejahterakan bangsanya. Dari segi ekologis, negara kepulauan tentu memiliki kekayaan sumber daya alam hayati, baik spesies hewan maupun tumbuhan. Hutan bakau yang tumbuh alami salah satu contohnya merupakan sumber daya alam hayati bagi keseimbangan ekosistem alam, sekaligus perlindungan garis pantai atau wilayah pesisir pantai. Selain itu, aneka ragam ikan yang melimpah, terumbu karang, rumput laut, dan masih banyak lagi, tentunya dapat membawa berkah bagi perekonomian bangsa Indonesia.
Adapun dengan kekayaan yang dimiliki Indonesia, ledakan penduduk yang dialaminya pun tak luput dari perhatian. Implikasi langsung dari pertambahan jumlah penduduk adalah semakin meningkatnya tuntutan kebutuhan hidup, sementara potensi sumberdaya alam di darat yang dimiliki sangat terbatas, sehingga hal tersebut mendorong untuk mengalihkan alternatif potensi sumberdaya alam lain yang kita miliki yaitu sumberdaya alam di lautan, termasuk wilayah pesisir pantai.

Kerusakan mangrove diantaranya disebabkan oleh tekanan dan laju pertambahan penduduk, terutama di daerah pesisir, sehingga mengakibatkan adanya perubahan tata guna lahan dan pemanfaatan sumberdaya alam secara berlebihan, akibatnya ekosistem hutan mangrove dengan cepat menipis dan rusak. Selain itu, meningkatnya permintaan terhadap produksi kayu menyebabkan eksploitasi berlebihan terhadap hutan mangrove. Kegiatan lain adalah pembukaan tambak-tambak untuk budidaya ikan, udang dan kepiting yang memberikan kontribusi besar bagi kerusakan hutan mangrove, sehingga fungsi dan ekosistem yang ada di sekitar mangrove menjadi hilang.

Kota ataupun desa yang berkembang di wilayah pesisir sangat berperan pada ekosistem laut dan menjadi bagian penting dalam menjaga kelangsungan hidup 
masyarakatnya. Pada kenyataannya, wilayah pesisir yang harusnya dikembangkan sebagai pelidung bagian daratan dan sumber daya yang melimpah umumnya tidak terjaga, sehingga mengalami kerusakan. Ekosistem hutan Mangrove di India, Vietnam dan Filipina lebih dari 50\% telah mengalami kerusakan selama 100 tahun terakhir. Indonesia sebagai negara yang memiliki hutan mangrove terluas di dunia dengan luas sekitar 3,8 juta ha atau $40 \%$ dari luas hutan mangrove dunia juga senantiasa mengalami kerusakan akibat kepentingan pertumbuhan ekonomi. (Ruslia, N: 1999, 24).

Undang-Undang No. 5 Tahun 1990 tentang Konservasi Sumberdaya Alam Hayati dan Ekosistem pada Bab I pasal 2 menjelaskan konservasi sumberdaya alam hayati adalah pengelolaan sumberdaya alam hayati yang pemanfaatannya dilakukan secara bijaksana untuk menjamin kesinambungan persediaannya dengan tetap memelihara dan meningkatkan kualitas keanekaragaman dan nilainya. Masyarakat harus bisa menjaga dan melestarikan sumberdaya alam yang ada agar selalu tetap terjaga dan berkelanjutan untuk generasi selanjutnya. Kondisi perairan laut Jawa Barat sebagaimana umumnya kondisi laut tropis yang selalu menerima cahaya matahari cukup optimal sepanjang tahun, memiliki arti penting bagi pertumbuhan jasad renik yang merupakan salah satu penyebab besarnya produktuvitas perairan laut tersebut.
Mangrove merupakan salah satu potensi sumber daya pesisir terbesar di Jawa Barat yaitu dengan luas sekitar seluas 33 . 740,83 ha. Potensi mangrove menyebar di Kabupaten Bekasi, Subang, Karawang, Indramayu, Cirebon, Leweng Sancang, Tasik, Sukabumi, dan Pelabuhan Ratu.

Pemerintah Provinsi Jawa Barat sebagai koordinator pembangunan di Jawa Barat, berdasarkan pasal 18 UU No. 32/ 2004, berwenang untuk mengelola sumber daya laut meliputi eksplorasi, konservasi, dan pengelolaan kekayaan laut. Dengan kewenangan tersebut, dengan tujuan untuk dapat mengurangi gap yang terjadi antara potensi, tingkat investasi dan produksi sumber kelautan.

Saat ini hampir di seluruh dunia terjadi peningkatan hilangnya sumberdaya mangrove yang disebabkan adanya pemanfaatan yang tidak berkelanjutan serta pengalihan peruntukan, hal yang sama juga terjadi di Indonesia. Potensi tinggi tersebut dibayangi dengan berbagai ancaman kerusakan ekosistem yang semakin lama semakin tinggi, baik secara alami maupun dengan adanya campur tangan manusia.

Penyusutan hutan mangrove tak terhindarkan pula di laut Kabupaten Bekasi, yakni laut Kecamatan Tarumajaya. Dari 10.481,15 hektare luas hutan mangrove yang dimiliki Bekasi, menyusut 1.000 hektare 
setiap tahun sejak 1997 hingga saat ini. Penyebab menyusutnya hutan mangrove tersebut disebabkan penebangan liar oleh masyarakat dan minimnya kesadaran masyarakat untuk memelihara tanaman mangrove tidak berbanding lurus dengan kerusakan alam dan lingkungan yang terjadi. Akibatnya, abrasi di wilayah pesisir laut Bekasi tidak terhindarkan

Dengan semakin menyusutnya hutan mangrove, maka peran pemerintah Kabupaten Bekasi sangat penting dalam mengontrol konservasi hutan mangrove, sekaligus mengajak kepada masyarakat untuk dapat menjaga, melestarikan dan memanfaatkan hutan mangrove secara berkelanjutan serta sebagai kawasan Pusat Restorasi dan Pembelajaran Mangrove (PRPM).

Hutan mangrove yang berada pada kawasan pesisir pantai PAL Jaya Desa Segarajaya Kecamatan Tarumajaya Kabupaten Bekasi ini berbatasan langsung dengan kawasan pesisir pantai Marunda Jakarta Utara. Melalui inisiatif dari beberapa pemuda setempat yang terhimpun dalam organisasi swadaya bernama Ikatan Pemuda Putera Daerah (IKAPUD), bersama dengan pemerintah daerah setempat , POKMASWAS, dan Dinas Kelautan Perikanan (DKP), masyarakat setempat diajak untuk menjaga dan mengelola hutan mangrove sebagai konservasi sumberdaya alam hayati sekaligus pengembangan ekowisata sebagai peningkatan perekonomian keluarga ataupun masyarakat setempat.

Untuk meminimalisir dampak yang lebih besar terhadap tekanan sumberdaya mangrove, masyarakat berupaya menanam mangrove dan ikut terlibat dalam pengelolaan mangrove. Pertengahan tahun 2016 lalu, Desa Segarajaya baru membuka kawasan pantai PAL Jaya sebagai lokasi wisata mangrove, sehingga ini dijadikan salah satu obyek yang mulai diminati. Partisipasi masyarakat sangat diperlukan dalam mengelola, menjaga dan melestarikan sumberdaya mangrove, agar kondisi alam maupun ekosistem laut tidak rusak. Melalui partisipasi masyarakat dalam mengelola hutan mangrove dengan sendirinya dapat meningkatkan kesadaran masyarakat terhadap lingkungan sekitar. Oleh karena itu, peneliti tertarik untuk melakukan penelitian tentang partisipasi masyarakat dalam mengelola hutan mangrove di Pantai PAL Jaya Desa Segarajaya, Kecamatan Tarumajaya, Bekasi.

Berdasarkan latar belakang masalah di atas, maka perumusan masalah penelitian ini adalah bagaimana partisipasi masyarakat dalam mengelola hutan mangrove di Pantai PAL Jaya Desa Segarajaya, mulai dari perencanaan, pelaksanaan, evaluasi, dan pemanfaatan? 


\section{Partisipasi Masyarakat}

Partisipasi menurut Keith Davis yang juga diungkapkan oleh Winardi (1990: 202) adalah turut sertanya seseorang, baik secara mental maupun secara emosional dalam memberikan sumbangsih-sumbangsih kepada proses pembuatan keputusan, terutama mengenai persoalan-persoalan terkait keterlibatan pribadi seseorang untuk melaksanakan tanggung jawabnya dalam melaksanakan hal tersebut.

Pengertian tersebut dapat diartikan bahwa partisipasi merupakan keterlibatan seseorang yang dipengaruhi kesadaran diri yang didasari oleh factor emosional orang tersebut dalam memberikan kontribusi berupa gagasan dan ikut bertanggungjawab di dalamnya.

Partisipasi masyarakat menurut Isbandi (2007: 27) adalah keikutsertaan masyarakat dalam proses pengidentifikasian masalah dan potensi yang ada di masyarakat, pemilihan dan pengambilan keputusan tentang alternatif solusi untuk menangani masalah, pelaksanaan upaya mengatasi masalah, dan keterlibatan masyarakat dalam proses mengevaluasi perubahan yang terjadi.

Terkait dengan beberapa pengertian tersebut di atas, partisipasi masyarakat dapat disimpulkan sebagai wujud dalam keseluruhan proses yang membutuhkan keterlibatan, baik aktif ataupun pasif dari seseorang ataupun sekelompok masyarakat secara sadar dan sukarela dalam kontribusinya pada suatu program atau kegiatan, mulai dari perencanaan, pelaksanaan, evaluasi sampai pada tahap pemanfaatan.

\section{Masyarakat Pesisir}

Secara sosiologis, karakteristik masyarakat pesisir umumnya berbeda dengan karakteristik masyarakat agraris. Masyarakat agraris yang direpresentasikan oleh kaum tani menghadapi sumber daya yang terkontrol, yakni pengelolaan lahan untuk produksi suatu komoditas dengan hasil yang relatif bisa diprediksi. Sementara masyarakat pesisir atau nelayan menghadapi sumberdaya yang hingga saat ini bersifat open access, sehingga karakteristik sumberdaya seperti ini menyebabkan nelayan berpindah-pindah untuk memperoleh hasil maksimal dengan ketidakpastian dan memiliki resiko yang tinggi. Kondisi sumber daya tersebut dapat menyebabkan nelayan memiliki karakter keras, tegas, dan terbuka. (Satria, 2015: 7-8).

Oleh sebab itu, tidak sedikit nelayan juga bekerja dan merangkap sebagai petani. Hal ini didukung dengan kondisi ekosistem yang memang kemungkinkan seperti tersedianya area lahan persawahan di sekitar pantai 
meskipun lahan pertanian tersebut sering terkena air laut.

Wilayah pesisir didefinisikan sebagai wilayah daratan yang berbatasan dengan laut, batas di daratan meliputi daerah-daerah yang tergenang air maupun yang tidak tergenang air yang masih dipengaruhi oleh proses-proses laut, seperti pasang surut, angin laut, dan intruisi garam, sedangkan batas di laut adalah daerah-daerah yang dipengaruhi oleh proses-proses alami di daratan seperti sedimentasi dan mengalirnya air tawar ke laut, serta daerah-daerah laut yang dipengaruhi oleh kegiatan-kegiatan manusia di daratan.

\section{Pengelolaan Hutan Mangrove}

Pengelolaan sumberdaya alam adalah upaya manusia dalam mengubah sumberdaya alam agar diperoleh manfaat yang maksimal dengan mengutamakan kontinuitas produksi (Soerianegara seperti yang dikutip Harahap 2001), begitu juga dengan pengelolaan ekosistem mangrove tersebut yaitu untuk mendapatkan produksi secara terus menerus dalam waktu yang relatif singkat demi mencapai suatu keadaan yang seimbang antara pertumbuhannya dengan hasil yang dipanen setiap tahun atau jangka waktu tertentu (Sofli, 2003). Tujuan utama pengelolaan hutan, termasuk hutan mangrove adalah untuk mempertahankan produktivitas lahan hutan sehingga kelestarian hasil merupakan tujuan utama pengelolaan hutan. Kelestarian produktivitas memiliki dua arti, yaitu kesinambungan pertumbuhan dan kesinambungan hasil panen.

Hutan mangrove adalah ekosistem hutan daerah pantai yang terdiri dari kelompok pepohonan yang bisa hidup dalam lingkungan berkadar garam tinggi. Salah satu ciri tanaman mangrove memiliki akar yang menyembul ke permukaan. Penampakan mangrove seperti hamparan semak belukar yang memisahkan daratan dengan laut.

\section{METODOLOGI}

Penelitian ini menggunakan metode penelitian deskriptif. Secara harfiah, penelitian deskriptif adalah penelitian yang bermaksud untuk membuat pencandraan (deskripsi) mengenai situasi-situasi atau kejadian-kejadian (Suryabrata, 2013: 76). Teknik pengambilan sampel dalam penelitian ini adalah menggunakan teknik non probability sampling yaitu dengan sampling purposive. Dalam memperoleh data di lapangan untuk mendeskripsikan dan menjawab permasalahan dalam penelitian, maka digunakan metode pengumpulan data, yaitu: observasi, kuesioner / angket, wawancara, dokumen, dan studi kepustakaan.

Setelah pengumpulan data dilakukan oleh peneliti, selanjutnya peneliti 
melakukan analisis data untuk memecahkan permasalahan dalam penelitian. Untuk memperoleh gambaran tentang partisipasi, data diolah dengan menggunakan teknik presentase dalam bentuk tabel yang dideskripsikan. Data yang diperoleh melalui kuesioner atau angket selanjutnya ditabulasikan ke dalam grafik. Analisis ini dimaksudkan untuk menggambarkan data hasil penelitian berdasarkan suatu sampel dan dari segi data yang diperoleh dalam analisis ini adalah sebuah gambaran secara umum tentang masalah yang dikaji. Menurut Sudjono (2010: 36 - 44) Untuk memperoleh persentase (frekuensi relatif) digunakan rumus sebagai berikut:

$$
\mathrm{P}=\frac{\mathrm{F}}{\mathrm{N}} \times 100 \%
$$

$$
\begin{aligned}
& \text { Keterangan: } \\
& \mathrm{P} \quad=\text { Angka Persentase } \\
& \mathrm{F} \quad=\begin{array}{l}
\text { Frekuensi yang sedang dicari } \\
\text { persentasenya }
\end{array} \\
& \mathrm{N} \quad \begin{array}{l}
\text { Number of Cases (Jumlah } \\
\text { Frekuensi/ Banyaknya } \\
\end{array} \\
& \begin{array}{l}
\text { Individu) } \\
100 \%=
\end{array} \\
& \text { Bilangan Konstanta }
\end{aligned}
$$

\section{HASIL DAN PEMBAHASAN}

Desa Segarajaya dibentuk tahun 1945 kemudian dimekarkan pada tahun 1984 menjadi Desa Segarajaya dan Desa Samudrajaya. Wilayah Desa Segarajaya adalah bagian dari desa di Kecamatan Tarumajaya Kabupaten Bekasi. Selain Desa Segarajaya, terdapat 7 desa lagi yang terdapat di Kecamatan Tarumajaya, di antaranya: Desa Pusakarakyat, Desa Setiasih, Desa Pahlawasetia, Desa Setiamulya, Desa Segaramakmur, Desa Pantaimakmutr, dan Desa Samudrajaya.

Desa Segarajaya sendiri terletak di daerah daratan rendah $\pm 0.5 \mathrm{Mdpl}$, memiliki jarak dengan Ibukota Kabupatensejauh \pm 40 Km, dengan luas wilayah 779,385 Ha. Adapun peta daerah penelitian Desa Segarajaya terdapat pada gambar 1 berikut ini:

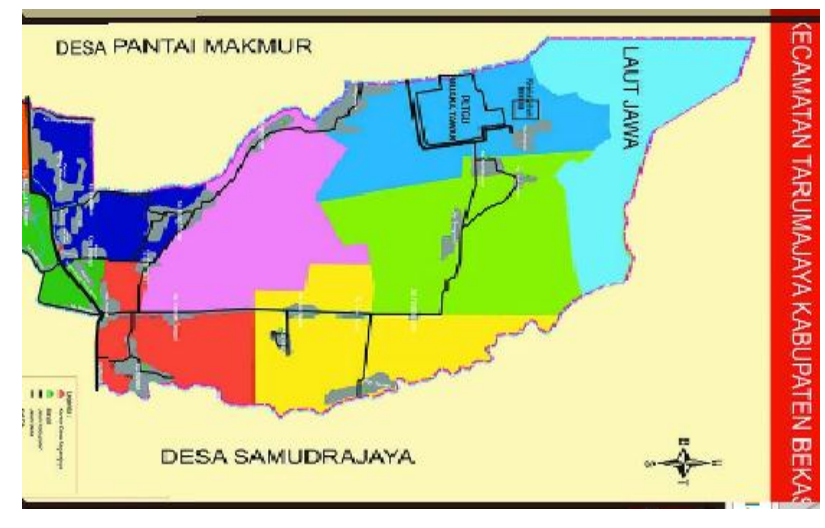

Gambar 1

Peta Desa Segarajaya

(Sumber:

https://sites.google.com/site/pemdabk/desa/segarajaya)

Desa Segarajaya merupakan wilayah administratif Kecamatan Tarumajaya, Kabupaten Bekasi dengan batas-batas sebagai berikut:

- Sebelah Utara: Laut Jawa 
- Sebelah Timur: Desa Samudrajaya

- Sebelah Selatan: Desa Pahlawan Setia

- Sebelah Barat: Desa Pantai Makmur Wilayah Desa Segarajaya terbagi menjadi 8 dusun yang terdiri dari 32 Rukun Warga (RW) dan 80 Rukun Tetangga (RT). Adapun jarak antar desa doi Desa Segarajaya

\begin{tabular}{|c|c|c|c|c|c|c|c|c|c|}
\hline KM & & & & & & & & & \\
\hline & 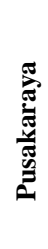 & 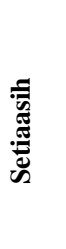 & 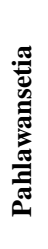 & 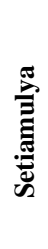 & 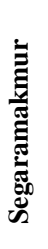 & 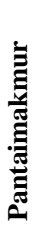 & 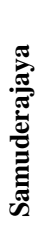 & 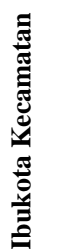 & 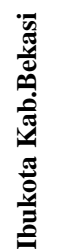 \\
\hline Segarajaya & 7,5 & 11,5 & 7,2 & 8,0 & 5,5 & 2,5 & 1,0 & 2,5 & 55,5 \\
\hline
\end{tabular}

terdapat pada tabel 1 sebagai berikut:

Tabel 1.

Jarak Antar Desa di Desa Segarajaya, Kecamatan Tarumajaya

Berdasarkan hasil penelitian peneliti pada masyarakat Desa Segarajaya, Kecamatan Tarumajaya, ditemukan data-data terkait partisipasi masyarakat dalam pengelolaan mangrove, mulai dari perencanaan, pelaksanaan, pemeliharaan/ evaluasi restorasi hutan mangrove, sampai dengan pemanfaatan hutan mangrove.

Partisipasi masyarakat dalam pelaksanaan mengelola hutan mangrove diperoleh persentase yang beragam, dengan total 25 responden. Persentase keikutsertaan masyarakat dalam kegiatan persemaian bibit mangrove sebesar 80\%, keterlibatan masyarakat dalam kegiatan pembibitan mangrove sebesar $80 \%$, keikutsertaan penanaman mangrove atas inisiatif sendiri sebesar $80 \%$, keikutsertaan masyarakat dalam penanaman mangrove bersama warga sekitar sebesar $76 \%$, penanaman mangrove yang digerakkan/ difasilitasi oleh lembaga lain sebesar $76 \%$, pembersihan lahan untuk kegiatan penanaman mangrove sebesar $80 \%$, merawat ekosistem mangrove yang sudah ditanam sebesar 44\%, mengajak rekan lain untuk terlibat dalam kegiatan restorasi mangrove sebesar $60 \%$, ikut serta dalam menggerakkan restorasi mangrove sekaligus memajukan ekoturisme sebesar $80 \%$.

Hasil penelitian terkait keterlibatan masyarakat dalam pemeliharaan dan evaluasi restorasi hutan mangrove, di antaranya: terdapat 14 responden dari 25 responden atau sebesar 56\% masyarakat yang terlibat dalam kegiatan evaluasi, 60\% masyarakat yang terlibat dalam kegiatan evaluasi/ pemeliharaan hutan mangrove bersama lembaga lain, terdapat 17 responden dari 25 responden atau sebesar 68\% masyarakat yang ikut serta hadir dalam pertemuan evaluasi pengelolaan hutan mangrove.

Kemudian hasil penelitian terkait partisipasi masyarakat dalam pemanfaatan hutan mangrove beragam. Persentase keikutsertaan masyarakat dalam memanfaatkan buah mangrove untuk kebutuhan dan meningkatkan ekonomi 
keluarga sebesar $80 \%$, memanfaatkan hutan mangrove sebagai peluang ekoturisme sebesar $84 \%$, keterlibatan pemanfaatan hutan mangrove sebagai sarana pendidikan lingkungan sebesar 72\%, kontribusi masyarakat dalam mengolah sampah di kawasan hutan mangrove sekaligus menyelamatan mangrove sebesar $56 \%$ dan ikut serta dalam memanfaatkan hutan mangrove yang bekerjasama dengan lembaga lain sebesar $68 \%$.

Desa Segarajaya Kecamatan Tarumajaya, Kabupaten Bekasi, memiliki kawasan hutan mangrove yang keberadannya baru dibuka sebagai kawasan wisata pada akhir tahunn 2016, sekaligus sebagai Pusat Restorasi dan Pembelajaran Mangrove (PRPM). Terkait dengan garis pantai, Bekasi memiliki garis pantai 72 kilometer, berada di tiga kecamatan di wilayah utara dan membentang dari perbatasan Jakarta sampai perbatasan Karawang. Kemudian data Bappeda Kabupaten Bekasi terdapat $6 \mathrm{~km}$ dengan luas hutan mangrove 15.000 hektar. Berdasarkan rencana Tata Ruang Wilayah Kabupaten Bekasi pada tahun 2003-2013 silam tiga kecamatan pesisir wilayah tersebut diarahkan untuk hutan lindung dengan ketebalan hutan minimal 500 meter dari bibir pantai, salah satunya Kecamatan Tarumajaya.

Berdasarkan pengamatan lapangan dan penelusuran data sekunder, kondisi hutan mangrove yang dulu rindang, tebal, kini rusak, karena abrasi dan kebijakan yang tidak mendukung terhadap lingkungan. Selain itu, penyusutan luas lahan mangrove dikarenakan terdapat penebangan batang kayu mangrove secara sembarang dan adanya alih fungsi lahan hutan mangrove oleh masyarakat sebagai lahan tambak.

Penyusutan atau perubahan tersebut, membuat kondisi alam di sekitar wilayah pesisir Pantai PAL Jaya kerap mengalami abrasi atau banjir rob biasanya dengan ketinggian $10 \mathrm{~cm}$. Hal tersebut secara tidak langsung berdampak pada keamanan dan kenyamanan lingkungan masyarakat pesisir, selain juga mengancam beberapa usaha tambak di sana. Salah satunya adalah lahan tambak yang sudah dimiliki perusahaan swasta, yakni PT. Hasanah Damai Putera.

Dari peristiwa tersebut, memunculkan kesadaran dari tokoh masyarakat Desa Segarajaya untuk melakukan pemulihan kembali dengan cara penanaman bibit pohon mangrove. Ide untuk membuka kawasan hutan mangrove pun disambut baik oleh masyarakat Desa Segarajaya dan mendapatkan bantuan pembangunan jembatan yang saat ini dikenal dengan "Jembatan Cinta" dari PT BJB UP Muara Tawar, sekaligus perapihan kawasan mangrove menjadi tempat wisata edukasi lingkungan (ekoturisme), hingga pada akhirnya beberapa kegiatan penanaman bibit diadakan.

Dengan menjadi kawasan restorasi mangrove yang merupakan program Dinas Kelautan dan Perikanan (DKP) dan dikelola 
oleh masyarakat Desa Sergarajaya, baik yang terhimpun dalam organisasi IKAPUD maupun tidak, maka penelitian ini dititikberatkan pada perolehan data keterlibatan aktif maupun pasif seseorang maupun kelompok masyarakat yang secara sadar dan sukarela berkontribusi pada program atau kegiatan, mulai dari perencanaan, pelaksanaan, perawatan/ evaluasi sampai pada tahap pemanfaatan di lapangan.

\section{KESIMPULAN}

Berdasarkan penelitian yang telah dilakukan, kesimpulan dari hasil penelitian ini di anataranya:

1. Dilihat dari pengisian angket dan data sekunder, keikutsertaan masyakarat dalam merencanakan dan melaksanakan pengelolaan hutan mangrove sudah cukup baik, begitu pun dengan kerjasama dengan lembaga lain. Hanya saja masih perlu sinergi yang kuat, sehingga sosialisasi maupun pelathan yang sudah diberikn bisa dialplikasikan secara konsisten.

2. Partisipasi masyarakat dalam mengelola hutan mangrove di Desa Segarajaya masih perlu ditingkatkan, terutama dari aspek keterlibatan masyarakat dalam perawatan bibit mangrove yang sudah ditanam. Hal itu dilihat dari masih rendahnya partisipasi masyarakat dalam hal merawat dan mengevaluasi program yang sudah dilakukan. Selama peneliti melakukan pengamatan lokasi, sampah masih belum dikelola dengan baik, sehingga akan mengancam ekosistem mangrove tersebut.

3. Kontribusi masyarakat dalam mengelola hutan mangrove masih minim, artinya perlu dimotivasi dan difasilitasi secara berkesinambungan.

4. Pemanfaatam hutan mangrove masih belum maksimal, belum ditemui masyarakat yang menjadikan buah mangrove sebagai bahan makanan yang memiliki nilai ekonomis. Pemanfatan hutan mangrove masih sebatas wisata edukasi, hal itu dikarenakan kawasan tersebut baru dibuka pada tahun 2016 silam dan menjadi kawasan Pusat Restorasi dan Pembelajaran Mangtrove.

Adapun rekomendasi yang diusulkan adalah sebagai berikut:

1. Perlu ada motivasi dari pemerintah kepada masyarakat agar partisipasi masyarakat lebih meningkat.

2. Perlu dilakukan pengawasan kepada masyarakat maupun pengunjung kawasan mangrove secara berkesinambungan, agar mangrove yang sudah direstorasi bisa terus terpelihara dan tidak tercemar.

3. Perlu dilakukan sosialisasi dan pemberdayaan secara berkala kepada masyarakat agar pemanfaatan mangrove bukan hanya sebagai tempat wisata dan 
kegiatan restorasi mangrove bisa terjaga secara optimal

\section{DAFTAR PUSTAKA}

Abdullah M Surjaya, Hutan Mangrove Laut Bekasi. Menyusut Ribuan Hektar (internet). (diunduh pada 22 Februari 2017) tersedia pada: https://metro.sindonews.com/read/11495 55/171/hutan-mangrove-laut-bekasimenyusut-ribuan-hektare-1477227027

Badan Pusat Statistik (BPS) Kabupaten Bekasi. Kecamatan Tarumajaya Dalam Angka. 2016

Dahuri, R, J. Rais, SP. Ginting, M. Sitepu. 2001. Pengelolaan Sumberdaya Pesisir dan Lautan Secara Terpadu. (Jakarta: Pradya Publishing).

Erwiantono. 2006. Kajian Tingkat Partisipasi Masyarakat Dalam Pengelolaan Ekosistem Mangrovedi Kawasan Teluk Pangpang-Banyuwangi. [internet]. (Diunduh pada 18 Februari 2017); 3 (1). Tersedia pada :https://agribisnisfpumjurnal.files.wordpr ess.com/2012/03/jurnal-vol-3-no-1erwin.pdf

Harahap N. 2010. Penilaian Ekonomi Ekosistem Hutan Mangrove dan Aplikasinya dalam Perencanaan Wilayah Pesisir. (Yogyakarta: Graha Ilmu)
Isbandi R. A. 2007. Perencanaan Partisipasi Berbasis Aset Komunitas: dari Pemikiran Menuju Penerapan. (Depok: FISIP UI Press).

Rasyida I, Nasdian FT. 2011. Partisipasi Masyarakat dan Stakeholder Dalam Penyelenggaraan Program Corporate Social Responsibility (CSR) dan Dampaknya Terhadap Komunitas Perdesaan. Jurnal Transdisiplin Sosiologi, Komunikasi, dan Ekologi Manusia. [Internet]. [Diunduh pada 23 Februari 2017]. Tersedia pada http://journal.ipb.ac.id/index.php/sodal ity/article /view/5832/4497

Ruslia, N., Khazali, M., Suryadiputra, I.N.N. 1999. Panduan Pengenalan Mangrove di Indonesia. Indonesia: Wetland Program.

Santoso N. 2006. Pengelolaan Ekosistem Mangrove Berkelanjutan di Indonesia. Dalam bahan pelatihan. 2006. "Training Workshop on Developing The Capacity of Environmental NGOs in Indonesia to Effectively Implement Wetland Project According to the Ramsar Guidelines and Obyectives of the Convention on Biodiversityee. Bogor. 
Satria, Arif. 2015. Pengantar Sosiologi Masyarakat Pesisir.Jakarta: Yayasan Pustaka Obor Indonesia

Sofli WA. 2003. Kajian Partisipasi Masyarakat dalam Pengelolaan Hutan Mangrove (internet). (Diunduh pada 22 Februari 2017). Tersedia pada: http://repository.ipb.ac.id/bitstream/ha ndle/123456789/8014/2003wrs. Pdf? sequence $=4 \&$ is Allowed $=\mathrm{y}$

Sudijono, Anas. 2010. Pengantar Statistik Pendidikan. Jakarta: Raja Grafindo Persada.

Suryabrata, Sumadi. 2013. Metodologi Penelitian. Jakarta: PT. Raja Grafindo Persada.

Syukur dkk. 2007. Analisis Kebijakan Pelibatan Masyarakat dalam mendukung Pengelolaan Hutan Mangrove di Kota Bontang. Jurnal Hutan dan Masyarakat. Vol. 14. No. 2 Desember 2007.

Surjaya M. Abdullah, 2016. Hutan Mangrove Laut Bekasi Menyusut Ribuan Hektare. (internet) (diunduh pada 20
Februari 2017) tersedia pada https://metro.sindonews.com/read/114 9555/171/ hutan-mangrove-lautbekasi- menyusut-ribuan-hektare1477227027.

Martunas, Yosafat, Hubungan Tingkat Partisipasi Masyarakat dalam Pengelolaan Ekosistem Mangrove (internet) (diunduh pada 10 Februari 2017) tersedia pada http://106.10.171.80/search/srpcache?. pdf

Yulianti. 2006. Partisipasi Masyarakat dalam Perbaikan dan Pemeliharaan Lingkungan Permukiman di Kelurahan Batu Sembilan Kecamatan Tanjung Pinang Timur. (internet). (diunduh 22 Februari 2017). Tersedia pada: http://eprints.undip.ac.id/17689/1/YU LIANTI.pdf

Winardi, 1990. Asas-Asas Manajemen (Bandung: mandar Maju. 1990)

Undang-Undang No. 5 Tahun 1990 tentang Konservasi Sumberdaya Alam Hayati dan Ekosistem pada Bab I pasal 2 